\title{
Influence of Lymphocyte T CD4 Levels on the Neuropsychological Performance of Population Affected by HIV and with a Previous History of Substance Use
}

\author{
Enrique Vázquez-Justo 1,2 *; Amalia García-Torres ${ }^{3,4}$; Esperanza Vergara-Moragues ${ }^{1,3,5}$ \\ ${ }^{1}$ Portucalense Institute of Neuropsychology. Universidade Portucalense, Porto (Portugal) \\ ${ }^{2}$ Policínico Êbam. Poio. Pontevedra (Spain) \\ ${ }^{3}$ Clinic Unit of Infectious Diseases. Clinical Hospital of Puerto Real, Cádiz (Spain) \\ ${ }^{4}$ Centro de Investigación Mente, Cerebro y Comportamiento (CIMCYC). University of Granada \\ (UGR), Granada (Spain) \\ ${ }^{5}$ Universidad Internacional de la Rioja (UNIR), Logroño (Spain)
}

Received 21 September 2016 | Accepted 1 November 2016 | Published 23 December 2016

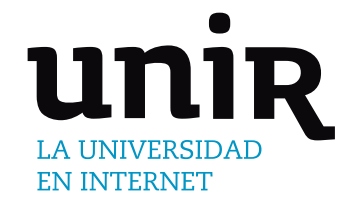

\section{KEYWORDS}

HIV, T CD4

Lymphocytes,

Neuropsychological

Evaluation.

\section{INTRODUCTION}

\begin{abstract}
I INCE the HIV primary infection the viral activity is continuous, and $\checkmark$ it produces the rise of a series of markers which will reflect the probability of HIV development at a certain speed. These markers show in a direct way (viral load, or lymphocytes T CD4) or in an indirect way (microglobulin B-2, neopterin, or antigen p24) the action HIV takes on the immunological system of the patient, and they have been used independently or combined to identify the risk of progression to AIDS [9] (Table I).
\end{abstract}

All these markers have a high prognostic value. In the case of lymphocytes $\mathrm{T} \mathrm{CD}$ 4, their number is the main indicator of the patient's immunological state. Its count is used for staging HIV infection, evaluating the risk of comorbidity or mortality, and the vulnerability to certain oportunistic infections, the need for its prophylaxis and the occasional discontinuation [1] [15]. Nowadays, the universal indication of anti-retroviral treatment (ART) is recognised for all patients, regardless of the lymphocyte CD4 count. Thus, the absolute

\footnotetext{
* Corresponding author.

E-mail address: enriquej@upt.pt
}

number and the percentage of lymphocytes CD4 must be periodically determined before initiating ART and, once it has been initiated, as a parameter of periodical monitoring of the immunological response to said treatment [15].

As far as the viral load is concerned, it must be determined during the initial assessment of the patient and before the beginning of ART, being the main parameter for the evaluation of ART's virological efficacy and to define the virological failure [7]. For all these reasons, we can conclude that the combination of these markers allows us to obtain a better overview of a patient's state, his/her prognosis and his/ her response to treatment.

HIV may affect the cognitive development of these patients [10], these specific markers have been studied regarding the presence of neuropsychological affectation, although results are not very consistent. As far as immunological markers are concerned, the lymphocyte T CD4 rate of decrease is a good indicator to determine the probability of developing AIDS [2] [27] [36], however, its efficiency to predict neurological and neuropsychological affectation has not been confirmed. While some authors point out that the probability of developing neuropsychological affectation is higher among seropositive patients with low levels of lymphocytes CD4 [26] [28] [29] [15], 
others, on the contrary, claim that there is no connection between the rate of lymphocytes T CD4 and neuropsychological functioning [14] [19] [21] [34]. In the end, immunological markers of HIV infection, specifically lymphocyte T CD4 count, have been associated to the presence of neuropsychological affectation in seropositive patients, though there does not seem to be an agreement about this in literature, which suggests the need for continuing research in order to clarify this subject.

For all these reasons, the objective of this article is to study the connection between lymphocytes T CD4 levels and the neuropsychological performance of former seropositive drug addicts.

TABLE I

Main Biological Markers of HIV Infection

(AdAPTED From García Soriano \& Miró,1999)

\begin{tabular}{|c|c|}
\hline \multicolumn{2}{|r|}{ Immunological markers } \\
\hline $\begin{array}{c}\text { Lymphocytes } \\
\text { TCD4: }\end{array}$ & $\begin{array}{l}\text { It is considered a severe immunodepression when the } \\
\text { lymphocyte CD } 4 \text { number, its percentage or the quotient } \\
\text { CD } 4 / C D 8 \text { is lower than } 200 / \mathrm{mm} 3,15 \% \text { or } 0,3 \text { respectively. }\end{array}$ \\
\hline $\begin{array}{c}\text { Microglobulin } \\
\beta-2:\end{array}$ & $\begin{array}{l}\text { It is present in all the nucleated cells, including lymphocytes } \\
\text { and macrofages. Its serum increase reflects the activation of } \\
\text { these cells. In homosexuals infected with HIV it has been } \\
\text { observed a progression of the infection when the plasmatic } \\
\text { levels are higher than } 5 \mathrm{~g} / \mathrm{ml} \text {. The results in drug addicts are } \\
\text { contradictory. }\end{array}$ \\
\hline Neopterin: & $\begin{array}{l}\text { It is produced by monocytes and macrofages stimulated with } \\
\text { interferon gamma produced by the activated lymphocytes } \\
\text { T. In HIV-infected homosexuals it has been observed a } \\
\text { progression of the infection with plasmatic levels higher } \\
\text { than } 20 \mathrm{nmol} / \mathrm{l} \text {. The results in drug addicts are variable. }\end{array}$ \\
\hline \multicolumn{2}{|r|}{ Virological markers } \\
\hline Antigen p24: & $\begin{array}{l}\text { It is detected at the beginning (acute infecction) and at the } \\
\text { end (AIDS) of the infection. It is not detected when the } \\
\text { patient has lymphocytes T CD } 4 \text { higher than } 500 / \mathrm{mm} 3 \text {. Its } \\
\text { apparition in an asymptomatic patient is a biological marker } \\
\text { of progression. It is seldom used at present. }\end{array}$ \\
\hline Viral load: & $\begin{array}{l}\text { Measured through PCR (detection limit } 200 \text { copies } / \mathrm{ml} \text { ), } \\
\text { bDNA (detection limit } 500 \text { copies } / \mathrm{ml} \text { ) y NASBA (detection } \\
\text { limit } 50 \text { copies } / \mathrm{ml} \text { ) from plasma or serum. Viral load is the } \\
\text { best prognostic and treatment-monitoring indicator. }\end{array}$ \\
\hline
\end{tabular}

\section{Methodology}

\section{A. Subjects}

This study is part of another one done on a wider population [32]. In order to conduct this research we have used a sample which comprised 80 males with a previous history of substance use, who voluntarily took part in the study, giving their informed consent. All the subjects for this study are former drug addicts with HIV infection. They were recruited at the Montecelo Hospital in Pontevedra, Xeral Cíes Hospital in Vigo, Xeral de Galicia Hospital in Santiago de Compostela and Juan Canalejo Hospital in A Coruña.

For the selection of the sample the professionals in the reference centres were informed of the requirements which the subjects for our study had to meet, and once selected, they were called at the centre, where the researcher informed them of the characteristics of the research, asking for their cooperation, and offering them the presentation of a report with all the results of the evaluation once it was complete. The subjects interested in taking part gave their informed consent and were called for the evaluation at the same centre where they had been selected, although some of them preferred taking the tests at the Faculty of Psychology in Santiago de Compostela.
We excluded from the study those subjects who showed, or had shown, neurological or medical pathologies that could affect the central nervous system, including dementia associated with HIV; psychiatric disorders; history of head trauma requiring hospitalization due to neurological complications; and antisocial personality disorder according to DSM-IV criteria (American Psychiatric Association, 1995). Also, we excluded subjects with moving or sensory defects, except in the case of visual ones corrected with lenses. Finally, based on the report from the professionals at the drug addict assistance units and the self-report from the subjects itself, we excluded those patients currently using psychotropic substances (illegal, medicine or alcohol) different from methadone.

Regarding the socio-demographic characteristics of the sample, $94 \%$ of the subjects presented right-hand dominance and 6\% left-handed. $60 \%$ had primary studies, and the remaining $40 \%$ secondary or higher studies. 33\% had a low socioeconomic level, and $67 \%$ a medium level. In terms of work situation, $40 \%$ were working when the study took place, and $60 \%$ were unemployed or retired (see Table II).

TABLE II.

Socio-demographic Characteristics of the Sample

\begin{tabular}{|cc|c|c|}
\hline & $\begin{array}{c}\text { HIV+ } \\
\text { N(\%) } \\
80(100)\end{array}$ & & \\
\hline \multicolumn{2}{|c|}{ Age* $^{*}$} & & \\
\hline Hand & Right & $94 \%$ & $73(91.2)$ \\
dominance & Left & $6 \%$ & $7(8.8)$ \\
\hline Level of & Primary & $60 \%$ & $55(68.7)$ \\
studies & Secondary or higher & $40 \%$ & $25(31.3)$ \\
\cline { 1 - 1 } Job & Not working & $60 \%$ & $57(71.2)$ \\
situation & Working & $40 \%$ & $23(28.8)$ \\
\cline { 1 - 1 } Economical & Low & $33 \%$ & $35(43.8)$ \\
level & Medium & $67 \%$ & $45(56.3)$ \\
\hline
\end{tabular}

* Mean and standard deviation

Regarding the clinical characteristics of the sample, 39\% of seropositive subjects were not having any antiretroviral treatment, unlike the remaining $61 \%$; in terms of viral load, in $44 \%$ of the cases it was undetectable, whereas in $56 \%$ it was detectable. As far as lymphocyte T CD4 level is concerned, $25 \%$ of seropositive subjects had a count higher than 500, in $29 \%$ it was $200-499$, and in $46 \%$ it was under 200 (see Table 3).

TABLE III.

Clinical Characteristics of the SAmple

\begin{tabular}{|c|c|c|}
\hline \multicolumn{3}{|c|}{$\mathrm{HIV}+$} \\
$\mathrm{N}(\%) 80(100)$ \\
\hline \multirow{2}{*}{ Antiretroviral treatment } & Yes & $61 \%$ \\
& No & $39 \%$ \\
\hline \multirow{2}{*}{ Viral load } & Detectable & $56 \%$ \\
& Undetectable & $44 \%$ \\
\hline \multirow{2}{*}{ Lymphocyte T CD4 } & $>500$ & $25 \%$ \\
& $200-499$ & $29 \%$ \\
& $<200$ & $46 \%$ \\
\hline
\end{tabular}

\section{B. Tools for Neuropsychological Assessment}

The tests included in the battery for neuropsychological exploration designed for this study were chosen because of their validity, and because they appeared to be sensitive to the neuropsychological deterioration in HIV-infected patients in other studies. We present below the list of tests used (Table 4) following the order of application, and clarifying the results collected with each test. 
TABLE IV.

Battery of Neuropsychological Exploration Used

\begin{tabular}{|l|l|}
\hline - WAIS IV: Comprehension, & - Benton's Visual Retention Test \\
Similarities, Digit Span, & - Boston Naming Test \\
Vocabulary, Digit Symbol, Block & - Stroop Test \\
$\begin{array}{l}\text { Design and Object Assembly } \\
\text { - Rey Auditory Verbal Learning Test }\end{array}$ & - Purdue's Pedgeboard Test \\
- Visual Search and Attention Test & - Rey-Osterrieth Complex Figure \\
- Trail-Making Test (parts A and B) & - Finger-Tapping Test \\
- Verbal Fluency Test & Wisconsin Card-Sorting Test \\
\hline
\end{tabular}

1. Wechsler Adult Intelligence Scale [35]. We used the following subtests from the Wechsler Adult Intelligence Scale (WAIS IV): Comprehension, Similarities, Digit Span, Vocabulary, Digit Symbol, Block Design and Object Assembly.

- Comprehension Subtest. It assesses the degree of appreciation of past experience applied to everyday situations, and of internalization of culture, especially of moral or ethical values. It consists of twelve open-ended questions, 14 common sense and practical reasoning questions, and 3 proverb questions that the subject must explain.

- Similarities Subtest. It is a test for verbal formation of concepts, which assesses the ability to assimilate and classify similarities and differences between objects, facts or ideas. It requires comprehension and associative thinking skills. The subject is asked to explain what a series of word pairs presented to him/ her have in common.

- Digit Span Subtest. It consists of two parts: forward digit span, in which the subject must repeat some series of numbers in the same order, and backward digit span, in which the subject repeats other series of numbers in reverse order. It assesses immediate auditory memory (backward digit span), attention (forward digit span), and resistance to distraction.

- Vocabulary Subtest. The subject must tell the meaning of 40 words presented to him in order of increasing difficulty, which allows us to assess classification and conceptualization skills. The score obtained in this test was also used to calculate the cognitive reserve.

- Digit Symbol Subtest. It assesses the ability to learn an unfamiliar task, visuomotor skill, the degree of persistence when doing an unattractive task, and the information processing speed. It consists of a sheet which shows the subject some numbers, from 1 to 9 , corresponding to a symbol, and a part where the numbers are, and in which the subject must draw the symbol corresponding to each number, as fast as possible in a limited time.

- Block Design Subtest. It assesses visuomotor integration, visuospatial organization, execution speed, and nonintellectual factors such as excessive care, impulsivity, and distraction. The task consists of having the subject perform a series of constructions according to a model using blocks and in a limited time.

- Object Assembly Subtest. It is a test for visuospatial organization speed and motor response, which assesses analysis skills and visual synthesis, visual and motor coordination. Sequential thinking also plays an important role in this test. The task consists of having the subject build figures from the pieces that he/she is given, in a limited time.

2. Rey's Auditory Verbal Learning Test [24]. It involves the reading, by the examiner, of a list of 15 words, which the subject must evoke immediately afterwards, in five different trials; and during a sixth evocation after an interference task (reading of 15 more words). It allows us to obtain seven scores, corresponding to the number of words evoked during the first five trials, a total score resulting from the addition of those, as well as the difference between the fifth and the sixth trials. This test allows us to asses immediate memory, it provides us with a learning curve, reveals inclinations towards patterns of retroactive and proactive interference, and measures the memory capacity after an interference.

3. Visual Search and Attention Test [31]. It is a test of visual cancellation which allows us to obtain a measurement of visual search skills and sustained attention. It comprises 4 sheets in which the subject must recognise and point out a certain letter or symbol among a series of distracting stimuli. With this test we obtain a score corresponding to the number of hits of the last two sheets.

4. Trail-Making Test [22]. It assesses skills of visual search and visuoconceptual and visuomotor exploration. It also assesses attention, mental flexibility, perceptive-motor skill and information processing speed. It consists of two tasks with separated scores, the score being the time that the subject needs to complete each task:

- Trails A, consisting of 25 circles numbered from 1 to 25 that the subject must join correlatively with a pencil stroke.

- Trails $B$, in which the 25 circles contain numbers from 1 to 13 and letters from A to L, the subject must join alternatively numbers and letters.

5. Verbal Fluency Test [6]. Its main objective is to assess verbal fluency. It consists of having the subject tell us as many words as possible starting with the letters F, A and S in three trials of one minute each. We get a score resulting from the addition of the number of words which the subject names with each letter.

6. Benton Visual Retention Test (Form C, Administration A) [5]. It assesses visuoconstructive skills, visual memory and visual perception, as well as spatial organization and visuospatial memory. It involves the presentation of ten sheets with printed figures for ten seconds each, asking the subject to reproduce them immediately once the stimulus sheet has been removed. This test gives us two scores: the number of sheets correctly reproduced, which measures the general efficiency of the execution, and the number of mistakes made.

7. Boston Naming Test [16]. It is a broad-spectrum figure-naming test, consisting of 60 sheets in which an object is represented, which the subject must name spontaneously, or with the help of a semantic or phonetic key. The score we obtain corresponds to the total number of figures named correctly.

8. Stroop Test [11]. It measures verbal fluency, cognitive efficiency, and the ability to inhibit stimuli which trigger automatic responses and, therefore, the ability to adapt perception and accommodate to new demands inhibiting a usual response in favour of an unusual one (cognitive flexibility). It consists of three sheets that the subject must read:

- In the first sheet, he/she must read the words red, green and blue printed in black ink, and randomly arranged in columns.

- In the second one, he/she must name the colour of ink with which some symbols "xxx" are printed.

- Finally, in the third sheet, the words red, green and blue appear printed with ink of those same colours. The subject must say the colour of the ink regardless of the written word.

A score is obtained for each sheet, consisting of the number of elements read in 45 seconds. We also calculate an interference score based on the score obtained in each sheet. 
9. Purdue Pegboard Test [30]. It assesses manual dexterity (speed and precision) in activities involving wide hand, finger and arm movements, and psychomotor coordination. The test consists of having the subject place a series of pegs in the holes set in rows on a board, first with his/her non-dominant hand, then with his/her dominant hand, and finally with both hands. We get three scores from the number of pegs placed during each part of the task and we also get a score resulting from the addition of the three parts.

10.Rey-Osterrieth Complex Figure Test [25]. It assesses constructive ability and visual memory, and it also allows us to assess cognitive processing ability, taking into account problem-solving strategies and organization and planning abilities. The test consists of having the subject copy a figure and after three minutes, without previous warning, reproduce it by heart. We get a score from the accuracy of the copy and another one from the reproduction by heart, also valuing the time spent in each one of them, as well as the strategy followed to copy the figure.

11.Finger-Tapping Test [23]. It assesses control, and psychomotor speed. It involves a board with a button connected to a counter, and the subject must tap with his/her index finger for 10 seconds. The final score is the average number of hits during 5 trials. A score is obtained for each hand.

12.Wisconsin Card-Sorting Test [13]. It allows us to obtain an assessment of abstract thinking. It is considered a measurement of executive functions and cognitive flexibility, as it requires some abilities to develop and maintain the strategy which is most appropriate to solve a problem while the stimulation conditions are changing. This measurement is considered to be sensitive to the frontal function. It consists of four stimulus cards and 128 response cards containing diversely-shaped figures (circles, crosses, triangles, stars), colours (green, blue, red, yellow), and a varied number of figures (one, two, three, four). The subject must match the response cards with the stimulus cards, deducing the criteria to do so correctly from the information given by the examiner in each trial. With this test we get multiple performance scores connected to the different cognitive processes: number of categories completed, fails in maintaining the category (inability to maintain an appropriate strategy); percentage of perseverative responses (persistence in responding according to a wrong criterion); percentage of perseverative and non-perseverative mistakes; and percentage of responses at a conceptual level (conceptual efficiency).

\section{Procedure}

Once the subject had fulfilled the criteria for taking part in the study, after getting some good therapeutic adherence, and before performing the neuropsychological exploration, we collected, according to the information provided by the subject's self-report, information regarding the personal background and medical history of interest, as well as relevant information about their history of drug abuse. Then, if no reason was deduced from the information to exclude the subject from the study, we would initiate the neuropsychological exploration using the protocol described in the material section, following the instructions indicated by the corresponding application manuals. The characteristics of the tests application were constant for every subject, and they were performed individually, in two sessions with the examiner of approximately 45 minutes.

III. RESULTS

\section{A. Lymphocytes TCD4}

In order to determine the level of immune compromise in the neuropsychological performance, we have divided the seropositive subjects in three groups, according to the lymphocyte T CD4 level $(\geq 500,499-200,<200)$ following the classification of the Centre for Disease Control (1992). The results are shown in Table 5, which presents the means and deviations typical from the groups in each one of the neuropsychological measures, and points out the relevant differences that have been observed, doing "post hoc" multiple comparison tests. In graphic 1 it is represented the performance of each group during the

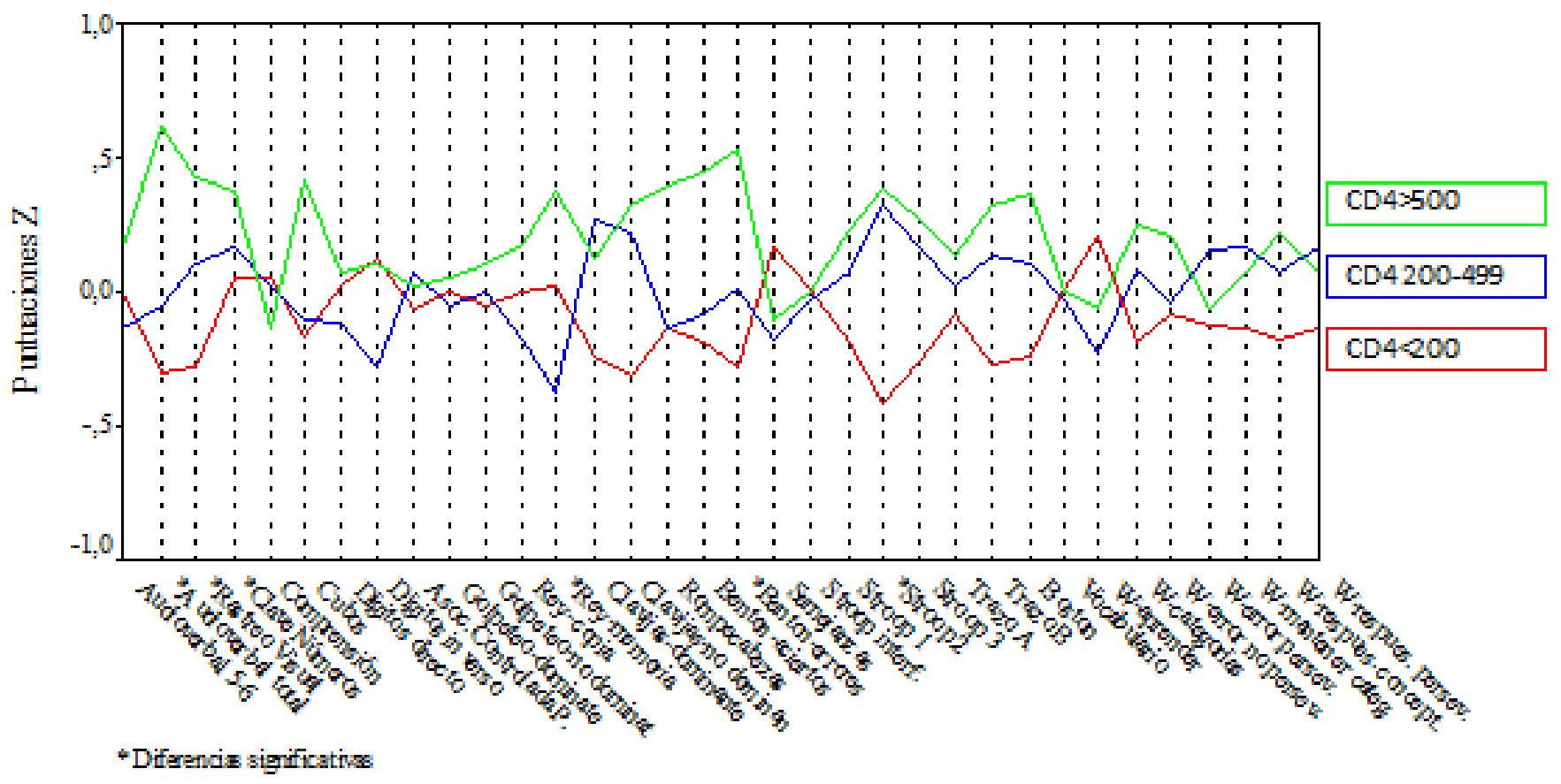

Fig. 1. Z scores from neuropsychological tests for seropositive drug addicts according to lymphocyte T CD4 level. 
different neuropsychological tasks, once the direct scores have been transformed into $\mathrm{Z}$ scores, and its direction has been corrected.

\section{B. Discussion}

The relation of lymphocyte T CD4 levels, used as immunological markers of the progression of HIV infection, have also been studied in connection with the presence of neuropsychological affectation, although the results are not consistent. While some studies point out that the lower the level of lymphocyte T CD4 in seropositive subjects, the greater the neuropsychological deterioration [26] [29] [28], others, on the contrary, show that cognitive functioning is not connected at all with this immunological marker [14] [19] [21] [34].

As far as our research is concerned, we have noticed a selective effect of the level of immune compromise in some attention and memory tasks. Our findings show that seropositive subjects with higher immunodepression levels $\left(\mathrm{CD} 4<200 / \mathrm{mm}^{3}\right)$ obtain a poorer performance than those whose lymphocyte T CD4 levels are within the range of normality, in the Auditory Verbal Learning Test, Visual Search and Attention Test, WAIS Digit Symbol, Benton Visual Retention Test, and Stroop Test, which leads us to suggest that only the subjects with a high degree of immune compromise are neuropsychologically vulnerable.

Taking into account our findings and the fact that the immunodepression level did not show its effect in verbal and denominational tasks, concept formation and reasoning, visuoconstructive skills, manual dexterity and motor speed, and frontal functions, we can suggest that the deterioration of the immunological system does not affect the neuropsychological performance in a general way, it does so in a selective way in attention and memory tasks.

These results are in accordance with those obtained in other studies with drug addict subjects during the different stages of infection [8] [28], as well as those obtained with homosexual subjects [4] [18]

TABLE V

Scores Obtained by Seropositive Former Drug Addicts in the Neuropsychologucal

Tests According to Lymphocyte T CD4 Levels [Mean (Standard Deviation)]

\begin{tabular}{|c|c|c|c|}
\hline \multicolumn{3}{|c|}{ HIV+ } & \multirow[b]{3}{*}{$\mathbf{F}$} \\
\hline \multicolumn{3}{|c|}{ Lymphocyte T CD4 level } & \\
\hline $\begin{array}{l}>\mathbf{5 0 0} \\
\mathrm{n}=\mathbf{2 0}\end{array}$ & $\begin{array}{c}499-200 \\
n=23\end{array}$ & $\begin{array}{l}<\mathbf{2 0 0} \\
\mathrm{n}=\mathbf{3 7}\end{array}$ & \\
\hline $13.40(4.15)$ & $14.13(4.00)$ & $14.19(4.05)$ & .26 \\
\hline $12.10(6.08)$ & $11.78(4.58)$ & $13.49(4.87)$ & .94 \\
\hline $6.00(1.12)$ & $5.78(1.28)$ & $5.95(1.18)$ & .20 \\
\hline $4.25(1.07)$ & $3.83(1.23)$ & $4.27(0.90)$ & 1.43 \\
\hline $42.30(13.88)$ & $41.91(13.24)$ & $42.32(12.00)$ & .00 \\
\hline $48.45(14.55)$ & $45.52(16.31)$ & $38.34(12.80)$ & 3.77 \\
\hline $34.55(8.38)$ & $29.96(9.78)$ & $29.43(7.90)$ & 2.48 \\
\hline $31.80(5.03)$ & $27.13(10.54)$ & $27.11(8.53)$ & 2.28 \\
\hline $1.65(1.87)$ & $2.26(1.60)$ & $1.97(2.07)$ & .55 \\
\hline $45.65(6.41)$ & $38.91(8.07)$ & $36.41(10.08)$ & 6.35 \\
\hline $129.40(25.92)$ & $117.43(39.55)$ & $102.86(36.19)$ & 3.91 \\
\hline $43.20(14.97)$ & $45.61(25.51)$ & $48.38(23.03)$ & .37 \\
\hline $89.60(41.28)$ & $101.04(59.89)$ & $128.65(76.96)$ & 2.72 \\
\hline $28.95(10.60)$ & $29.43(11.08)$ & $28.03(9.44)$ & .14 \\
\hline $7.25(1.62)$ & $6.13(2.40)$ & $5.95(1.90)$ & 2.92 \\
\hline $4.05(2.95)$ & $6.17(4.10)$ & $7.41(4.17)$ & 4.85 \\
\hline $54.63(2.29)$ & $53.23(5.47)$ & $51.30(6.25)$ & 2.63 \\
\hline $99.40(19.12)$ & $96.26(22.44)$ & $90.89(17.33)$ & 1.37 \\
\hline $68.75(13.95)$ & $67.57(16.44)$ & $55.54(14.83)$ & 6.92 \\
\hline $39.35(10.40)$ & $37.87(14.61)$ & $32.54(11.78)$ & 2.43 \\
\hline$-1.33(8.31)$ & $-1.62(8.29)$ & $-1.28(7.28)$ & .01 \\
\hline $13.70(2.36)$ & $14.09(2.33)$ & $12.78(2.72)$ & 2.08 \\
\hline $13.30(2.20)$ & $13.09(1.76)$ & $11.81(2.53)$ & 3.76 \\
\hline $31.30(2.25)$ & $29.89(4.92)$ & $30.55(3.66)$ & .73 \\
\hline $17.25(4.74)$ & $12.96(7.49)$ & $15.22(4.83)$ & 3.17 \\
\hline $42.81(8.85)$ & $41.60(10.65)$ & $42.24(12.73)$ & .06 \\
\hline 38.89 (7.95) & $37.87(8.87)$ & $37.31(10.47)$ & .17 \\
\hline $4.15(1.90)$ & $3.83(2.08)$ & $3.22(2.11)$ & 1.50 \\
\hline$-6.39(12.36)$ & $-8.00(10.45)$ & $-3.66(7.54)$ & 1.05 \\
\hline $20.39(14.25)$ & $19.16(10.88)$ & $22.94(14.41)$ & .61 \\
\hline $14.67(8.40)$ & $17.58(13.67)$ & $18.13(10.98)$ & .64 \\
\hline $0.90(1.17)$ & $0.78(0.95)$ & $1.17(1.50)$ & .69 \\
\hline $54.06(23.15)$ & $50.29(23.32)$ & $44.68(22.40)$ & 1.17 \\
\hline $23.49(18.50)$ & $21.81(13.58)$ & $27.22(19.19)$ & .73 \\
\hline
\end{tabular}

a) Differences between CD4 $>500$ y CD4 $<200(p<.05)$

b) Differences between CD4 $>500$ y CD4 499-200 (p $<.05)$

c) Differences between CD4 499-200 y CD4 $<200(p<.05)$ 
[29], which describe problems of attention, verbal fluency and manual dexterity.

However, in some of the studies carried out with seropositive homosexuals, both asymptomatic and symptomatic, no connection between immune deterioration and neuropsychological performance has been described [3] [19] [21] [34], and Heaton and collaborators do not describe it either (1995) [14] with seropositive heterosexual subjects during different stages of the infection, despite having used the same neuropsychological tasks as we did.

Our hypothesis is that the differences between the results obtained in these studies and ours can be due not only to the fact of using different risk groups, but also to the classification used to determine immunodepression levels. In this regard, some authors use as an immunodepression criterion values under 400 or 500 lymphocytes T CD4/mm3 [21], whereas we have grouped together the subjects according to the current classification of HIV infection (CDC, 1992) which provides three differencial levels of immunodepression. That is why when using levels of immune compromise with broader ranges the possibility of finding differences in the neuropsychological performance are reduced. On the other hand, we also must consider that some studies argue that lymphocytes T CD4 are the best immunological marker of neuropsychological deterioration in seropositive drug addicts [36], while in homosexuals the best predictor seems to be microglobulin ß-2 [17]

On balance, our results support a direct relation between the lymphocyte T CD4 rate and the neuropsychological performance in seropositive people with a previous history of substance use in attention and memory tasks, whereas we do not observe this relation in the rest of skills assessed, which allows us to confirm that the processes of attention and memory decline with the deterioration of the immune system. Therefore, we consider that the deterioration of the immune system can be regarded as a risk factor for neuropsychological manifestations in seropositive former drug addicts during the different stages of the infection. These results provide necessary advances in this field, and studies in this way will have to be conitnued in order to keep working towards the progress of knowledge in the affectation of the lymphocyte T CD4 rate on HIV+ patients.

\section{REFERENCES}

[1] D. Asboe, C. Aitken , M. Boffito , C. Booth, P. Cane, A. Fakoya, et al. (2012). British HIV Association guidelines for the routine investigation and monitoring of adult HIV-1-infected individuals. HIV Medicine. Volume 13, Issue 1, January, Pages 1-44.

[2] A. Balagopal, D.M. Asmuth, W.T. Yang, T.B. Campbell, N. Gupte, N. and L. Smeaton (2015). Pre-cART Elevation of CRP and CD4+ T-Cell Immune Activation Associated With HIV Clinical Progression in a Multinational Case-Cohort Study. Journal of Acquired Immune Deficiency Syndromes, Volume 70, Issue 2, October, Pages 166-71.

[3] M. R. Basso and R.A. Bornstein (2000). Effects of inmunosuppression and disease severity upon neuropsychological function in HIV infection. Journal of Clinical and Experimental Neuropsychology, Volume 22, Issue 1, February, Pages 104-114.

[4] J. T. Becker, L. Kingsley, J. Mullen, B. Cohen, E. Martin, E.N. Miller, A. Ragin, N. Sacktor, O.A. Selnes, B.R. Visscher; Multicenter AIDS Cohort Study (2009). Vascular risk factors, HIV serostatus, and cognitive dysfunction in gay and bisexual men. Neurology, Volume 73, Issue 16, October, Pages 1292-1299.

[5] A.L. Benton (1981). Test de retención visual de Benton. Madrid: TEA.

[6] A.L. Benton and K.S. Hamsher (1978). Multiligual Aphasia Examination. Iowa City: University of Iowa.

[7] Documento de consenso de Gesida/Plan Nacional sobre SIDA respecto al tratamiento antirretroviral en adultos infectados por VIH (2016). Recuperado de : http://www.gesida-seimc.org/guias_clinicas.php?mn $\mathrm{MP}=406 \& \mathrm{mn} \_\mathrm{MS}=407$

[8] R. Farinpour, E. Martin, M. Seindenberg, D. Pitrak, K. Pursell, K.
Mullane, R. Novak, and M. Harrow (2000). Verbal working memory in HIV-seropositive drug users. Journal of International Neuropsychological Society, Volume 6, Issue 5, July, Pages 548-555.

[9] F. García, A. Soriano and J. Miró (1999). Marcadores serológicos e inmunológicos de la infección por VIH. En V. Soriano and J. GonzálezLahoz (Eds.), Manual del SIDA, pages 640-653. Madrid: IDEPSA.

[10] A. García-Torres, E. Vergara-Moragues, A. Piñón-Blanco A y M. PérezGarcía (2015). HIV-related neuropsychological impairment in patients with previous substance use: A preliminary study. Revista Latinoamericana de Psicología, Volum 47, Issue 3, July, Pages 213-221.

[11] C. J.Golden (1994). Test de colores y palabras Stroop. Madrid: TEA.

[12] Grupo, de, expertos, Gesida, y, Secretaría, del, Plan, Nacional, sobre, Sida. (2014). Documento de consenso sobre el manejo clínico de los trastornos neurocognitivos asociados a la infección por el virus de la inmunodeficiencia humana (enero 2013). Enfermedades Infecciosas y Microbiología Clínica, Volume 32, Pages 37-47.

[13] R. K.Heaton, G.J. Chelune, J. L. Talley, G. Kay, G and C. Curtis (1993). Wisconsin Card Sorting Test Manual: Revised and expanded. USA: Psychological Assesment Resources.

[14] R. Heaton, I. Grant, N. Butters, D. White, D. Kirson, D, J. Atkinson, J. McCutchan, M. Taylor, M. Kelly, R. Ellis, T. Wolsof, R. Velin, T. Marcotte, J. Hesselink, T.Jernigan, J. Chandler, M. Wallace, Y. Abrason and The HNRC Group. (1995). The HNRC 500-neuropsychology of HIV infection at different disease stages. Journal of the International Neuropsychological Society, Volume 1,Issue 3, May, Pages 231-251.

[15] Insight Start Study Group, J. Lundgren , A. Babiker, F.Gordin , S. Emery, B. Grund et al.(2015). Initiation of antiretroviral therapy in early asymptomatic HIV infection. The New England Journal of Medicine, Volume 373, Issue 9, August, Pages 795-807.

[16] E. Kaplan, H. Goodglass and S. Weintraub. (1986). Test de Vocabulario de Boston. Madrid: Panamericana.

[17] A. Lifson, N. Hessol and G. Rutherford (1992). Progression and clinical outcome of infection due to human immunodeficiency virus. Clinical Infectious Disease, Volume 14, issue 4,April, Pages 966-972.

[18] K. Marder, X. Liu, Y. Stern, R. Malouf, G. Dooneief, K. Bell, G. Todak, G. Joseph, S. Sorrell, W. El-sadr, J. Willians, A. Ehrhardt, Z. Stein and J. Gorman (1995). Risk of human immunodeficiency virus type 1-related neurologic disease in a cohort of intravenous drug users. Archives of Neurology, Volume 52, Issue 12, December, Pages 1174-1182.

[19] E. Miller, O. Selnes, J. McArthur, P. Satz, J. Becker, B. Cohen, K. Sheridan, A. Machado, W. Van Gorp and B. Visscher (1990). Neuropsychological performance in HIV-1 infected homosexual men: The Multicenter AIDS Cohort Study (MACS). Neurology, Volume 40, Issue 2, February, Pages 197-203.

[20] A.Olson, A. Walker, A. Suthar, C. Sabin, H. Bucher, I. Jarrin, S. Moreno, S. Perez-Hoyos, K. Porter and D. Ford (in press). Limiting Cumulative HIV Viremia Copy Years by Early Treatment Reduces Risk of AIDS and Death. Journal of acquired immune deficiency syndromes.

[21] R. Podraza, C. Bornstein, M. Whitacre, R. Para, R. Fass, R. Rice and H. Nasrallah (1994). Neuropsychological performance and CD4 levels in HIV-1 asymptomatic infection. Journal of Clinical and Experimental Neuropsychology, Volume 6, Issue 5, October, 777-783.

[22] R. Reitan (1992). Trail Making Test: Manual for administration and scoring. Tucson: Reitan Neuropsychology Laboratory.

[23] R. Reitan (1979). Finger Tapping Test. Arizona: Reitan Neuropsychology Laboratory.

[24] [24] A.Rey (1964). L'examen Clinique en Psychologie. París: Presses Universitaries.

[25] A. Rey (1987). Test de copia de una figura compleja. Madrid: TEA.

[26] R. Schrier, S. Hong, M. Crescini, R. Ellis, J. Pérez-Santiago, C. Spina, S. Letendre. HNRP Group (2015). Cerebrospinal fluid (CSF) CD8+ T-cells that express interferon-gamma contribute to HIV associated neurocognitive disorders (HAND). Plos One, Volume 10, Issue 2, Frebruary, doi: 10.1371/ journal.pone.0116526.

[27] A. Schwartländer, B. Bek, H. Skarabis, J. Koch, J. Burkowitz and M. Koch, For The Multicentre Cohort Study Group. (1993). Improvement of the predictive value of CD4+ lymphocite count by $\beta_{2}$-microglobulin, immunoglobulin A and erythrocyte sedimentation rate. AIDS, Volume 7, Issue 6, June, Pages 813-821.

[28] R. Stern, S. Silva, N. Chaisson and D. Evans (1996). Influence of cognitive 
reserve on neuropsychological functioning in asymptomatic human immunodeficiency virus-1 infection. Archives of Neurology, Volume 53, Issue 2, Frebruary, Pages 148-153.

[29] Y. Stern, K. Liu, K. Marder, G. Todak, M. Sano, A. Ehrhardt and J. Gorman (1995). Neuropsychological changes in a prospectively followed cohort of homosexual and bisexual men with and without HIV infection. Neurology, Volume 45, Issue 3, March, Pages 467-472.

[30] J. Tiffin (1948). Purdue Pegboard. Indiana: Lafayette Instrument.

[31] M. Trenerry, B. Crosson, J. Beboe, and W. Leber (1990). Visual search and attention test. Florida: Psychological Assesment Resources.

[32] E. Vázquez-Justo, E. Vergara-Moragues, A. Piñón-Blanco, C. GuillénGestoso and M. Pérez-García (in press). Neuropsychological functioning in methadone maintenance patients with HIV. Revista Latinoamericana de Psicología.

[33] E. Vázquez-Justo, E. Vergara-Moragues, A. Piñón-Blanco, C. GuillénGestoso and M. Pérez-García (2014). Cognitive reserve during neuropsychological performance in HIV intravenous drug users. Applied Neuropsychology: Adult, Volume 21, Issue 4, November, Pages 288-296. doi: 10.1080/23279095.2013.813852.

[34] G. Villa, A. Salida, E. Moro, M. Tovadozza, A. Antinori, A. De Luca, R. Murri and E. Tamburrini (1996). Cognitive impairment in asymptomatic stoges of HIV infection. A longitudinal study. European Neurology, Volume 36, Issue 3, Pages 125-133.

[35] A. Wechsler (1995). Escala de Inteligencia de Weschler para adultos. Madrid: TEA.

[36] J. Zabay, J. Sempere, J. Benito, B. Gonzalez, E. Obregón, J. Díez, J and E. Fernandez-Cruz (1995). Serum $\beta_{2}$-microglobulin and prediction of progresion to AIDS in HIV-infected injection drug users. Journal of Acquired Immune Deficiency Syndromes and Human Retrovirology, Volume 8, Issue 3, March, Pages 266-272.

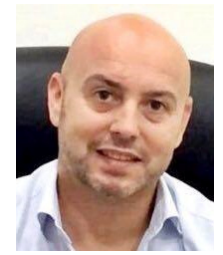

Enrique Vázquez-Justo

He has a Ph.D. in Psychology. He is a professor in the Department of Psychology and Education and Director of Portucalense Institute of Neuropsychology and Cognitive and Behavioral Neuroscience at the Portucalense University of Oporto. He is also Director of Ebam Clinics (Pontevedra, Spain) where he works in neuropsychological intervention. Moreover, he has collaborated and currently collaborates in several national and international Postgraduate courses in Neuropsychology. He has published articles in journals of international and national renown. He also works as a reviewer for international journals in the field of Neuropsychology and Neuroscience.

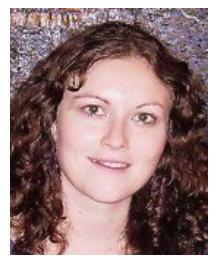

\section{Amalia García Torres}

Amalia García Torres is a Psychologist by the University of Granada and Master's Degree in Psychology of Health and in Neuropsychology. She currently works as a psychologist in GERASA (Chiclana de la Frontera, Cadiz, Spain) with HIV patients with social exclusion. She is also working on her doctoral thesis about "Cognitive Rehabilitation in HIV patients" and she is member for the research group "Neuropsychology and Clinical Psychoneuroimmunology" (CTS-581) at the University of Granada. During the past few years, she has participated in several national and international conferences on drug addiction and HIV. Moreover, she has published several scientific papers related to neuropsychology, addictions and HIV.

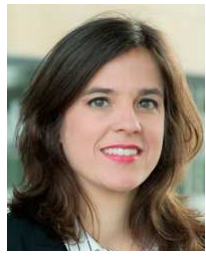

\section{Esperanza Vergara-Moragues}

Esperanza Vergara-Moragues has a Ph.D. in Psychology and she is expert in Clinical Psychopathology and Neuropsychology. She works as associate professor at the Universidad Internacional de La Rioja (UNIR) and she is member of the research groups "UNIR Research" and "Neuropsychology and Clinical Psychoneuroimmunology" (CTS-581) at the University of Granada. She has collaborated in several postgraduate courses in national and international universities. Also she collaborates at the Portucalense University of Oporto. Moreover, she has published and collaborate as a reviewer a wide array of recognized articles (journal citation report) about Neuropsychology and Psychopathology. 